\title{
Application of Direct Marketing Tools in the Nonprofit Sector. The Albanian Case
}

\author{
Author: Xhiliola Agaraj (Shehu)
}

Business Department, Faculty of Economy University "Ismail Qemali" of Vlora, Albania

\section{Doi:10.5901/ajis.2013.v2n8p344}

\begin{abstract}
Non-profit organizations rely on direct marketing tactics to attract the target market. Managers of nonprofit organizations use direct marketing to attract donors, recruit volunteers and attract beneficiaries. Direct marketing tools are used by non-profit organizations for many years. This concept was expanded to include not only mail but any medium that provides a two-way communication with the target audience. The development of technology in this field has created new communication possibilities, although traditional methods are still effective. The purpose of this paper is to identify what are the forms of direct marketing used by non-profit organizations operating in Albania in attracting the target market. Information will be provided about the use of direct marketing tools to attract donors, volunteers, and beneficiaries by type of nonprofit organizations and their location. Secondary data helped to obtain information on the use of direct marketing tool by non-profit organizations while primary data helped to obtain information on the use of direct marketing by non-profit organizations operating in Albania. For primary data collection were used questionnaires to the non-profit organizations operating in Albania. For the interpretation of primary data, extracting conclusions and recommendations are used focus groups, representatives of whom were executive directors of nonprofit organizations.
\end{abstract}

Keywords: Direct Marketing, nonprofit sector,

\section{Introduction}

Direct marketing is a communication and sale channel that allows businesses and nonprofits organizations to communicate straight to the customer, with advertising techniques that can include direct mail, email, interactive consumer websites, online display ads, fliers, catalog distribution, promotional letters, and outdoor advertising.

Direct mail fundraising is a form of direct marketing widely used by nonprofit organizations in North America and Europe to recruit or "acquire" new donors or members and to inform, cultivate and "upgrade" the level of their contributions or dues. The technique has been shown to work equally well in many other countries across the globe. Its use is spreading quickly.

The professional use of direct mail fundraising requires an understanding both of the principles and practice of direct marketing and of the discipline of fundraising. In direct marketing, practitioners view large numbers of prospects or donors through the lens of statistics. Fundraising teaches us how to view prospects or donors as individuals, with unique values, beliefs, and preferences.

In its modern form, direct mail fundraising appeared in the United States after World War II, when nationwide charities such as the National Easter Seal Society sought ways to broaden their fundraising base.

Direct mail fundraising has its own unique jargon, much of it related to the art and science of creating, producing and mailing the right appeal to the right list at the right time, and measuring the results.

Direct marketing is attractive to many marketers because its positive results can be measured directly. For example, if a marketer sends out 1,000 solicitations by mail and 100 respond to the promotion, the marketer can say with confidence that campaign led directly to $10 \%$ direct responses. This metric is known as the 'response rate,' and it is one of many clearly quantifiable success metrics employed by direct marketers. In contrast, general advertising uses indirect measurements, such as awareness or engagement, since there is no direct response from a consumer.

Measurement of results is a fundamental element in successful direct marketing. The Internet has made it easier for marketing managers to measure the results of a campaign. This is often achieved by using a specific website landing page directly relating to the promotional material. A call to action will ask the customer to visit the landing page, and the effectiveness of the campaign can be measured by taking the number of promotional messages distributed (e.g., 1,000) and dividing it by the number of responses (people visiting the unique website page). Another way to measure the results is to compare the projected sales or generated leads for a given term with the actual sales or leads after a direct 
advertising campaign.

While many marketers recognize the financial benefits of increasing targeted awareness, some direct marketing efforts using particular media have been criticized for generating poor quality leads, either due to poor message strategy or because of poorly compiled demographic databases. This poses a problem for marketers and consumers alike, as advertisers do not wish to waste money on communicating with consumers not interested in their products.

Some of these concerns have been addressed by direct marketers by the use of individual "opt-out" lists, variable printing, and better-targeted list practices. Additionally, in order to avoid unwanted mailings, members of the marketing industry have established preference services that give customers more control over the marketing communications they receive in the mail.

Consumers have expressed concerns about the privacy and environmental implications of direct marketing. In response to consumer demand and increasing business pressure to increase the effectiveness of reaching the right customer with direct marketing, companies specialize in targeted direct advertising to great effect, reducing advertising budget waste and increasing the effectiveness of delivering a marketing message with better geo-demography information, delivering the advertising message to only the customers interested in the product, service, or event on offer. Additionally, members of the advertising industry have been working to adopt stricter codes regarding online targeted advertising.

\section{Literature Review}

Any medium that can be used to deliver a direct communication to a customer can be employed in direct marketing, including:

E-mail marketing: Sending marketing messages through email is one of the most widely used direct-marketing methods. One reason for email marketing's popularity is that it is relatively inexpensive to design, test, and send an email message. It also allows marketers of nonprofit sector to deliver messages and to accurately measure responses.

Online tools: With the expansion of digital technology and tools, direct marketing is increasingly taking place through online channels. Most online advertising is delivered to a focused group of customers and has a track-able response.

- Display Ads are interactive ads that appear on the Web next to content on Web pages or Web services. Formats include static banners, pop ups, videos, and floating units. Customers can click on the ad to respond directly to the message or to find more detailed information.

- Social Media Sites, such as Facebook and Twitter, also provide opportunities for direct marketers to communicate directly with customers by creating content to which customers can respond.

Mobile. Through mobile marketing, marketers engage with prospective customers and donors in an interactive manner through a mobile device or network, such as a cellphone, smartphone, or tablet. Types of mobile marketing messages include: SMS: (short message service) - marketing communications are sent in the form of text messages, also known as texting. MMS: (multi-media message service). These messages use elements such as images, video, and audio.

Telemarketing: Another common form of direct marketing is telemarketing, in which marketers contact customers by phone. The primary benefit to businesses is increased lead generation, which helps businesses increase sales volume and customer base. The most successful telemarketing service providers focus on generating more "qualified" leads that have a higher probability of getting converted into actual sales.

Voicemail Marketing: Voicemail marketing emerged out of the market prevalence of personal voice mailboxes, and business voicemail systems. Voicemail marketing presented a cost effective means by which to reach people directly, by voice. More recently, businesses have utilized guided voicemail (an application where pre-recorded voicemails are guided by live callers) to accomplish personalized business-to-business marketing formerly reserved for telemarketing. Because guided voicemail is used to contact only businesses, it is exempt from Do Not Call regulations in place for other forms of voicemail marketing. Voicemail courier is a similar form of voicemail marketing with both business-to-business and business-to-consumer applications.

Broadcast Faxing: Broadcast faxing, in which faxes are sent to multiple recipients, is now less common than in the past. Also due to the popularity of a variety of digital communication methods, the overall use of faxes is less than in the past.

Couponing: Couponing is used in print and digital media to elicit a response from the reader. An example is a coupon which the reader receives through the mail and takes to a store's check-out counter to receive a discount. 
Digital Coupons: Manufacturers and retailers make coupons available online for electronic orders that can be downloaded and printed. Digital coupons are available on company websites, social media outlets, texts, and email alerts. There are an increasing number of mobile phone applications offering digital coupons for direct use.

Direct Response TV: Direct marketing via television (commonly referred to as DRTV) has two basic forms: long form (usually half-hour or hour-long segments that explain a product in detail and are commonly referred to as infomercials) and short form, which refers to typical 30-second or 60-second commercials that ask viewers for an immediate response (typically to call a phone number on screen or go to a website). TV-response marketing can be considered a form of direct marketing, since responses are in the form of calls to telephone numbers given on-air. This allows marketers to reasonably conclude that the calls are due to a particular campaign, and enables them to obtain customers phone numbers as targets for telemarketing.

Direct Mail: The term "direct mail" is used to refer to communications sent to potential customers or donors via the postal service and other delivery services. Direct mail is sent to customers based on criteria such as age, income, location, profession, buying pattern, etc.

Direct mail includes advertising circulars, catalogs, free-trial CDs, pre-approved credit card applications, and other unsolicited merchandising invitations delivered by mail to homes and businesses.

Direct Response Radio: In direct response radio, ads contain a call to action with a specific tracking mechanism. Often, this tracking mechanism is a "call now" prompt with a toll-free phone number or a unique Web URL. Results of the ad can be tracked in terms of calls, orders, customers, leads, sales, revenue, and profits that result from the airing of those ads.

Out-of-home direct marketing refers to a wide array of media designed to reach the consumer outside the home, including billboards, transit, bus shelters, bus benches, aerials, airports, in-flight, in-store, movies, college campus/high schools, hotels, shopping malls, sport facilities, stadiums, taxis, that contain a call-to-action for the customer to respond.

Magazine and newspaper ads often include a direct response call-to-action, such as a toll-free number, a coupon redeemable at a brick-and-mortar store, or a QR code that can be scanned by a mobile device - these methods are all forms of direct marketing, because they elicit a direct and measurable action from the customer.

Direct selling is the sale of products by face-to-face contact with the customer, either by having salespeople approach potential customers in person, or through indirect means such as Tupperware parties.

The door-to-door distribution of leaflets within a local community is a form of direct marketing used extensively by restaurants, fast food companies, and many other business and nonprofit sector focusing on a local catchment.

\section{The Use of direct marketing tools in nonprofit sector to attract target market.}

Among the direct marketing tools used by nonprofit organizations (NPOs) that operate in Albania to communicate with donors is e-mail, as it is associated with a lower cost and higher profit. $84 \%$ of NPOs see as more effective use of e-mail to communicate with donors. Direct communications tools with effectiveness above average are direct mail, phone and face to face communication. This is because direct mail is free but is not very profitable, and can not be used for all types of communication.

While the phone and face to face communication are effective in communication but may be associated with a higher cost, and that is why they have this level of use. Telemarketing is not used. NPOs should make more effort to have more individual donors and donations from private businesses through telemarketing which is an effective tool for NPOs operating in international markets (Figure 1).

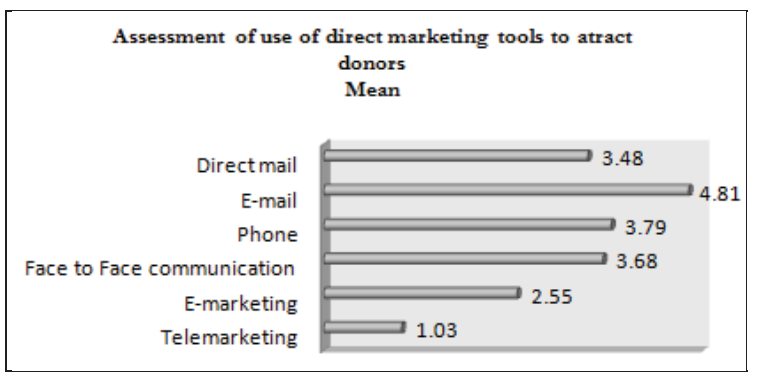

Figure 1. Assessment of the use of direct marketing tools to attract donors

If you look at the level of use of these tools by type of NPO conclude that telemarketing is not used, have a high level of 
use of e-mail, and other tools as face-to-face communication, phone and direct mail have an average use. Levels of use of these tools don't depend by the type of NPO ( Table 1)

\begin{tabular}{lccccc}
\hline $\begin{array}{l}\text { Assessment of use of direct marketing } \\
\text { tools to attract donors by type of NPOs. }\end{array}$ & Min & Max & Association & Foundation & Center \\
\hline Telemarketing & 1 & 5 & 1.05 & 1.00 & 1.00 \\
Face to face communication & 1 & 5 & 3.62 & 3.89 & 3.70 \\
Mobile & 1 & 5 & 3.83 & 3.78 & 3.74 \\
E-mail & 1 & 5 & 4.83 & 5.00 & 4.73 \\
Direct mail & 1 & 5 & 3.63 & 3.11 & 3.40 \\
E- marketing & 1 & 5 & 2.37 & 2.5 & 2.82 \\
\hline
\end{tabular}

Table 1: Assessment of use of direct marketing tools to attract donors by type of NPOs.

If you look at the level of use of direct marketing tools to attract donors by location, conclude that telemarketing isn't used by NPOs that belong to different areas and have a high level of use email regardless of location of NPOs. If we look at other levels of use of direct marketing tools they have an average level of use (table 2).

\begin{tabular}{lccccc}
\hline $\begin{array}{l}\text { Assessment of use of direct marketing } \\
\text { tools to attract donors by location of NPOs. }\end{array}$ & Min & Max & Tirana & North & South \\
\hline Telemarketing & 1 & 5 & 1.05 & 1.00 & 1.00 \\
Face to face communication & 1 & 5 & 3.66 & 3.63 & 3.79 \\
Mobile & 1 & 5 & 3.67 & 3.88 & 3.95 \\
E-mail & 1 & 5 & 4.68 & 4.88 & 5.00 \\
Direct mail & 1 & 5 & 3.26 & 3.83 & 3.50 \\
E- marketing & & & & & \\
\hline
\end{tabular}

Table 2: Assessment of use of direct marketing tools to attract donors by location of NPOs.

If you look at the level of use of direct marketing tools to attract donors conclude that telemarketing as a tool of direct marketing isn't use to attract donors. Are used other tools of direct marketing and has a high level of use e-mail. If we look at the statistical significance of the relationship between the level of use of direct marketing tools and providing funds conclude that relationship has a statistically significant because:

- There is a statistically significant the relationship between the level of face to face communication and securing funding from foreign donors.

- There is a statistically significant the relationship between the level of use of e-mail and secure funds from foreign donors.

- For both cases test Che Squre is smaller than the interval of reliability 0.05 .

\begin{tabular}{|c|c|c|c|c|c|}
\hline $\begin{array}{l}\text { Assessment of use of direct } \\
\text { marketing tools to attract donors. }\end{array}$ & Government & $\begin{array}{l}\text { Individual } \\
\text { Donors }\end{array}$ & $\begin{array}{l}\text { Private } \\
\text { Business }\end{array}$ & Foundations & $\begin{array}{c}\text { International } \\
\text { Donators }\end{array}$ \\
\hline Telemarketing & 1,06 & 1,00 & 1,11 & 1,07 & 1,03 \\
\hline Face to face communication & 3,67 & 3,83 & 3,70 & 3,79 & 3,71 \\
\hline Mobile & 3,85 & 3,86 & 3,86 & 3,83 & 3,81 \\
\hline E-mail & 4,67 & 5,00 & 4,85 & 4,97 & 4,85 \\
\hline Direct mail & 3,48 & 3,20 & 3,32 & 3,25 & 3,46 \\
\hline
\end{tabular}

Table 3: Assessment of use of direct marketing tools to attract donors.

Face-to-face communication is one of the direct marketing tools that is used to attract beneficiaries. It is characterized by an average of 3.80 which means that there is a level of use above average. This tool of direct communication is used by $58 \%$ of NPOs to inform and convince beneficiaries that can provide for free the service of the organization. If we compare the use of e-mail to communicate with beneficiaries notice that it is an average level of use, because it is not very effective communication tool, since not all beneficiaries have the opportunity to communicate by e-mail. The phone has e 
low level of use because it is expensive and beneficiaries are numerous. Direct mail isn't used because of distance, which is small. Telemarketing is a tool that should provide the opportunity by own NPOs (figure 2).

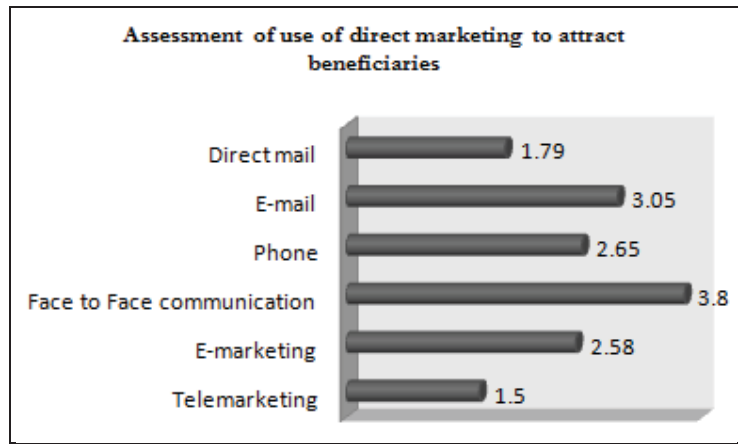

Figure 2. Assessment of the use of direct marketing tools to attract beneficiaries.

If you look at the level of use of direct marketing tools to attract beneficiaries, by type and location of the NPO, we conclude that the level of their use does not depend by the type or location of the NPO (table 4).

\begin{tabular}{|l|c|c|c|}
\hline Direct marketing tools & Association & Foundation & Center \\
\hline Telemarketing & 1,10 & 1,00 & 1,00 \\
\hline E-marketing & 2,39 & 2,50 & 2,89 \\
\hline Face to Face communication & 3,62 & 3,89 & 4,03 \\
\hline Phone & 2,64 & 2,67 & 2,65 \\
\hline E-mail & 3,10 & 3,00 & 3,00 \\
\hline Direct mail & 2,00 & 1,67 & 1,55 \\
\hline
\end{tabular}

Table 4: Assessment of use of direct marketing tools to attract beneficiaries by type of NPOs.

Among the most commonly used tools of direct communication with volunteers is e-mail that is characterized by a high level of use, and the phone has an average use in those NPOs which have less volunteers and is little used as a communication tool in those NPOs which was characterized by many volunteers. Face-to-face communication is little used. Telemarketing is not very effective in communication and direct mail also because the distance is shorter and there are other faster tools of communication.

Among the direct marketing tools used to attract volunteers is e-mail, the phone and face to face communication have an average level of use, regardless type and location of NPOs. Direct mail is little used (figure3).

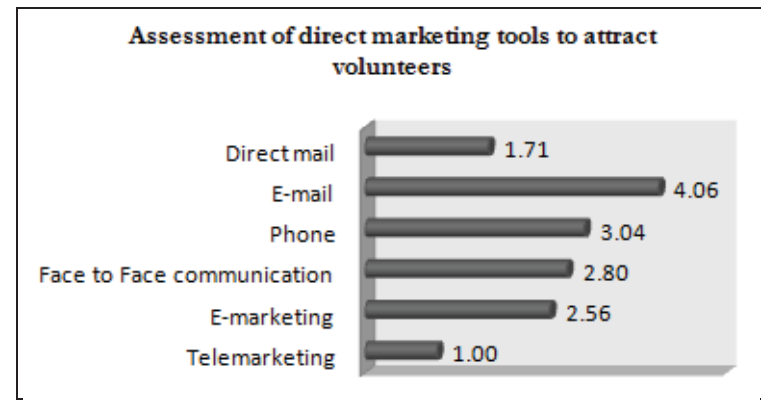

Figure 3: Assessment of direct marketing tools to attract volunteers.

Among the direct marketing tools used to attract volunteers is e-mail, the phone and face to face communication have an 
average level of use, regardless type and location of NPOs. Direct mail is little used.

\section{Conclusion and Recommendation.}

Among the direct marketing tools used to communicate with donors, characterized by a high level of use is e-mail and have an above average level of use, phone, face-to-face communication, and direct mail. The telemarketing is not used to attract donors. The level of use of direct marketing tools does not depend by the type and location of NPOs.

Among the direct communication tools that have a higher level of use in attracting beneficiaries is face to face communication which is used but not much. In the opinion of NPOs use of face-to-face communication is necessary to attract beneficiaries if we talk about social centers. Other tools of direct marketing are e-mail which has an average use, phone, direct mail has a low level of use and telemarketing isn't used to attract beneficiaries. There is no relationship between the level of usage of direct marketing and the type or location of NPOs.

Direct communication tools used to communicate with volunteers is e-mail which is less costly, phone and face to face communication which has an average use, has a low level of use direct mail and telemarketing is not used.

Direct marketing tools that aren't used to attract donors and that should be paid attention by NPOs are telemarketing and e-marketing. In other countries they are more important tools used to secure funding from donors and to attract beneficiaries and volunteers.

\section{References}

Edwart Nash (2001) Direct Marketing: Strategy, Planning, Execution, 4th ed, McGraw Hill Professional,

Jeffrey Dobkin, (April 30, 2007), Successful Low Cost Marketing Methods (Marketing and Direct Marketing), $3^{\text {rd }}$ ed, Danielle Adams Pub Jeffrey Dobkin (September 10, 2008) Direct Marketing Strategies: Forget Theory - Here's What Really Works, $4^{\text {th }}$ ed, The Danielle Adams Publishing Company

Nat.G Bodian (February 1, 1995) Direct Marketing Rules of Thumb: 1,000 Practical and Profitable Ideas to Help You Improve Response, Save Money, and Increase Efficiency in Your Direct Program 1 1 st McGraw-Hill

Robert Bly (April 11, 1998) Business to Business Direct Marketing, $2^{\text {nd }}$ edition, McGraw-Hill;

Bob Stone, Ron Jacobs (November 14, 2007) Successful Direct Marketing Methods, 8 edition McGraw-Hill;

Dan.S Kennedy ( April 2013) Direct Marketing, 2nd ed, Entrepreneur Press;

Drayton Bird, (3 Jun 2007), Common sense Direct and Digital Marketing, $5^{\text {th }}$ ed, Kogan Page

Matthew Housden, Brian Thomas, (19 Feb 2002), , A Butterworth-Heinemann Title

Brian Thomas, Matthew Housden, (27 Jan 2011), Direct Marketing in Practice (Marketing Series: Practitioner), $2^{\text {nd }}$ ed, A \& C Black Publishers Ltd 